\title{
Regiochemistry of the Reaction between Dibenzothiophene Radical Cation and Nucleophiles or Nitrogen Dioxide
}

\author{
Craig P. Butts, ${ }^{a}$ Lennart Eberson, ${ }^{b, *}$ Michael P. Hartshorn, ${ }^{a, *}$ Finn Radner, ${ }^{b_{1}} \dagger$ \\ Ward T. Robinson ${ }^{a}$ and Bryan R. Wood ${ }^{a}$
}

${ }^{a}$ Department of Chemistry, University of Canterbury, Christchurch, New Zealand and ${ }^{\mathrm{b}}$ Chemical Center, Lund University, PO Box 124, S-221 00 Lund, Sweden

\begin{abstract}
Butts, C. P., Eberson, L., Hartshorn, M. P., Radner, F., Robinson, W. T. and Wood, B. R., 1997. Regiochemistry of the Reaction between Dibenzothiophene Radical Cation and Nucleophiles or Nitrogen Dioxide. - Acta Chem. Scand. 51: 839-848. (C) Acta Chemica Scandinavica 1997.

The regiochemistry of nucleophile or radical attack upon dibenzothiophene radical cation $\left(2^{+}\right)$has been studied, using the photolysis of 2 -tetranitromethane, the $\mathrm{NO}_{2}$ or nitrous acid catalyzed (NAC) nitration of 2 and the silver(II) mediated acetoxylation of $\mathbf{2}$ as test reactions in all likelihood mediated by $\mathbf{2}^{+}$. The results are discussed in relation to theoretical predictions based on the VBCM model.

The photolysis of the charge-transfer complex of 2 and tetranitromethane in dichloromethane gives mainly dibenzothiophene sulfoxide (3) and minor amounts of 2-nitrodibenzothiophene (4), r-1-hydroxy-c-4-trinitromethyl-1,4-dihydrodibenzothiophene (5), $t$-2-nitro-r-1-trinitromethyl-1,2-dihydrodibenzothiophene (6) and $c$-1-nitro-r-4-trinitromethyl-1,4-dihydro-dibenzothiophene 7. In acetonitrile the major product is the sulfoxide 3 together with 2-nitrodibenzothiophene (4) and 4-nitrodibenzothiophene (9). The photolysis in 1,1,1,3,3,3-hexafluoropropan-2-ol yields only the sulfoxide 3 and minor amounts of the 2-nitroarene 4.

Nitration of 2 by $\mathrm{NO}_{2}$ in dichloromethane gives largely 3 and the 2-nitro isomer 4, as does NAC nitration in acetic acid.

The oxidation of 2 by an $\mathrm{Ag}^{\text {II }}$ complex of 2,2'-bipyridine gave mainly 1- and 4-acetoxydibenzothiophene and a minor proportion of the 3 -acetoxy isomer, no sulfoxide 3 being formed.

The X-ray crystal structure is reported for compound $\mathbf{5}$.
\end{abstract}

Dedicated to Professor Dr. Hans Schäfer, University of Münster, on the occasion of his 60th birthday.

The valence bond configuration mixing (VBCM) model, in combination with high-level quantum chemical theory (CASPT2), was recently applied to predict the regioselectivity of reactions of radical cations of a few nonalternant systems with nucleophiles. ${ }^{1}$ Predictions for nucleophilic attack upon dibenzofuran radical cation $\left(1^{+}\right)$generally agreed well with experimental results. ${ }^{2}$ The reaction between $\mathbf{1}^{+}$and a radical $\left(\mathrm{NO}_{2}\right)$ showed the regiochemistry expected from a consideration of the spin density distribution in $\mathbf{1}^{+}$in its ${ }^{2} \mathrm{~A}_{2}$ state. ${ }^{3}$

For dibenzothiophene radical cation $\left(2^{+}\right)$the theoretical treatment predicted that the interaction with a nucleophile should lead to substitution predominantly at the 3- and 1-positions, with only a minor contribution from reaction at the 2- and 4-positions (Fig. 1). Also attack at sulfur should be a minor pathway. The need for two

\footnotetext{
* To whom correspondence should be addressed.

$\dagger$ Present address: Astra-Draco AB, PO Box 34, S-221 00 Lund, Sweden.
}

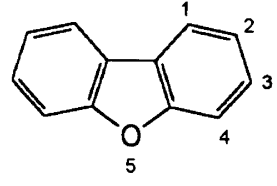

1

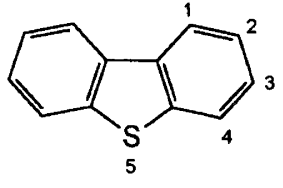

2 reactivity indices per position precludes a more quantitative analysis. On the other hand, reaction between $2^{+}$ and a radical should occur predominantly at sulfur and in the 2-and 4-positions, as predicted from the theoretical distribution of spin density in $\mathbf{2}^{+}$. An EPR spectral study of $\mathbf{2}^{+}$showed that the carbon positions of highest spin density are indeed $\mathrm{C} 2$ and $\mathrm{C}_{4}{ }^{4}$ Since little is known about the regioselectivity of $2^{+}$reactions, ${ }^{*}$ we have performed an exploratory study of possible ways

\footnotetext{
* The only example of substitution into $2^{+}$has been described in the anodic oxidation of $\mathbf{2}$ in acetonitrile where a cationic
} $S$-to-C2 connected dimer of 2 was claimed to be formed. ${ }^{5}$ 


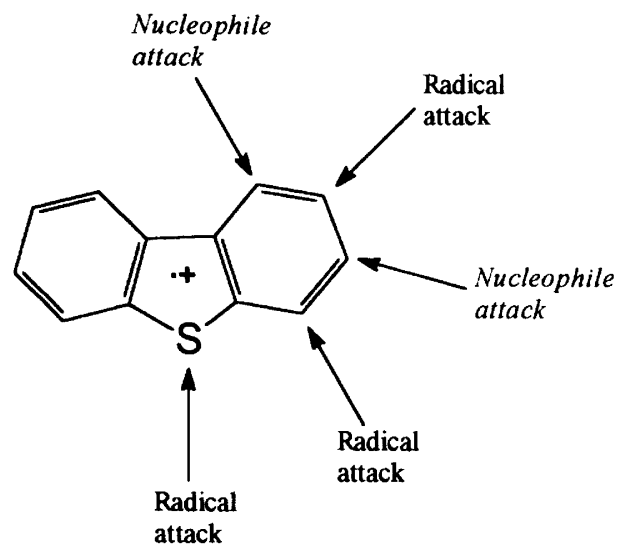

Fig. 1. Major centres of attack by radicals and nucleophiles upon $2^{+}$, as predicted from quantum chemical calculations (Ref. 1).

to obtain reactivity indices experimentally for comparison with the theoretical values. The reactions chosen are (i) the photochemical reaction between 2 and tetranitromethane, (ii) oxidative acetoxylation of 2 by $\mathrm{Ag}^{\mathrm{II}}$-acetate ion and (iii) nitration of 2 by $\mathrm{NO}_{2}$. As outlined below, these reactions are strongly indicated to proceed via $2^{+}$. and thus may supply the information required to judge the theoretical results. We now report some exploratory results from such studies.

\section{Results}

Photochemistry of dibenzothiophene 2 and tetranitromethane under various conditions. The photochemical addition of tetranitromethane to aromatic compounds $\mathrm{ArH}$ has been shown to occur predominantly by addition of the elements of tetranitromethane, $-\mathrm{NO}_{2}$ or -ONO (most often ending up as $-\mathrm{OH}$ under the conditions employed) and $-\mathrm{C}\left(\mathrm{NO}_{2}\right)_{3}$, across the aromatic ring. ${ }^{6,7}$ The initial reaction has been shown ${ }^{8}$ to be the attack of the nucleophile, trinitromethanide ion, at a ring position, followed by attack of $\mathrm{NO}_{2}$ upon the neutral carbon radical [eqn. (1)]. The nitro- and/or nitritotrinitromethyl adducts are either stable enough to permit isolation or undergo more or less facile elimination of nitroform and/or nitrous acid to give substitution products $\mathrm{ArNO}_{2}$ and/or $\operatorname{ArC}\left(\mathrm{NO}_{2}\right)_{3}$. Thus the point of attachment of trinitromethanide ion in the various products will in principle provide an indication of the regioselectivity of $\mathrm{ArH}^{+}$.

$$
\begin{aligned}
& \mathrm{ArH}+\mathrm{C}\left(\mathrm{NO}_{2}\right)_{4} \stackrel{h v}{\longrightarrow} \mathrm{ArH}^{\cdot}+\mathrm{NO}_{2}\left(\mathrm{NO}_{2}\right)_{3} \mathrm{C}^{-} \\
& \rightarrow \operatorname{Ar}(\mathrm{H})\left(\mathrm{NO}_{2}\right) \mathrm{C}\left(\mathrm{NO}_{2}\right)_{3}+\mathrm{Ar}(\mathrm{H})(\mathrm{ONO}) \mathrm{C}\left(\mathrm{NO}_{2}\right)_{3} \\
& \underset{\text { or }-\mathrm{HNO}_{2}}{-\mathrm{HC}\left(\mathrm{NO}_{2}\right)_{3}} \mathrm{ArNO}_{2}+\mathrm{ArC}\left(\mathrm{NO}_{2}\right)_{3}
\end{aligned}
$$

A solution of dibenzothiophene 2 and tetranitromethane in dichloromethane was irradiated at $20^{\circ} \mathrm{C}$. The composition of the reaction mixture was monitored by withdrawing samples for NMR spectral analysis
(Table 1). The final solution (after $5 \mathrm{~h}$ ) contained a mixture of dibenzothiophene sulfoxide (3) $(56 \%)$, the 2-nitroarene $4(11 \%)$, hydroxy-trinitromethyl adduct 5 (4\%), nitro-trinitromethyl adducts $6(1 \%)$ and $7(4 \%)$, unidentified aromatic compounds (total 12\%) and unidentified adducts (total 11\%). The separation and identification of products 3, 4, 6 and 7 were performed as described in Experimental.

The structure of adduct 5 was determined by single crystal X-ray analysis. A perspective drawing of $r-1$ hydroxy- $c$-4-trinitromethyl-1,4-dihydrodibenzothiophene $5, \mathrm{C}_{13} \mathrm{H}_{9} \mathrm{~N}_{3} \mathrm{O}_{7}$, is presented in Fig. 2, and the corresponding atomic coordinates are given in Table 2. For a discussion of the structure, see Experimental.

At $-20^{\circ} \mathrm{C}$ in dichloromethane, the photolysis of dibenzothiophene-tetranitromethane gave similar product mixtures as the reaction at $20^{\circ} \mathrm{C}$ above (Table 1 ).

The product compositions for the analogous photochemical reaction in acetonitrile at $20^{\circ} \mathrm{C}$ are given in Table 1. No adducts were observed among the products, but the yields of dibenzothiophene sulfoxide $\mathbf{3}$ and 2-nitrodibenzothiophene 4 were higher than in reactions in dichloromethane and in addition some 4-nitrodibenzothiophene 9 was formed. A reaction in acetonitrile at $-20^{\circ} \mathrm{C}$ was not possible because of the low solubility of the substrate.

The photolysis of dibenzothiophene-tetranitromethane at $20^{\circ} \mathrm{C}$ in 1,1,1,3,3,3-hexafluoropropan-2-ol (HFP) gave product mixtures containing dibenzothiophene sulfoxide (3) (ca. 85\%), 2-nitrodibenzothiophene (4) (ca. 12\%), and minor amounts of unidentified aromatic compounds (Table 1).

Oxidative acetoxylation of 2 . The radical cation mediated oxidation of aromatics by an $\mathrm{Ag}^{\mathrm{II}}$ complex with 2,2'bipyridine in the presence of acetate ion can be achieved by heating a mixture of a catalytic amount of a silver(I) salt with $\mathrm{ArH}$, sodium or potassium peroxydisulfate and $2,2^{\prime}$-bipyridine in acetic acid containing sodium acetate to $40^{\circ} \mathrm{C}$ for an extended period [eqns. (2)-(4)]..$^{9}$

$\mathrm{Ag}^{\mathrm{I}}+\mathrm{S}_{2} \mathrm{O}_{8}{ }^{2-} \rightarrow 2 \mathrm{Ag}^{\mathrm{II}}+2 \mathrm{SO}_{4}{ }^{2-}$

$\mathrm{Ag}^{\mathrm{II}}+\mathrm{ArH} \rightarrow \mathrm{Ag}^{\mathrm{I}}+\mathrm{ArH}^{\cdot+}$

$\mathrm{ArH}^{+}+\mathrm{AcO}^{-} \rightarrow \mathrm{ArOAc}$

Applied to 2, this method after $16 \mathrm{~h}$ gave a $39 \%$ yield of a mixture of 1-acetoxydibenzothiophene (53\%), 3-acetoxydibenzothiophene (9\%) and 4-acetoxydibenzothiophene $(37 \%)$. The yield of the 2-acetoxy isomer was $\leqslant 1 \%$ (limit of detection). No sulfoxide 3 was formed.

Several other oxidative acetoxylation processes were tried, but gave only trace amounts of acetoxy products (anodic acetoxylation in acetic acid-sodium acetate) ${ }^{10}$ or other products (nitration products from cerium ammonium nitrate in acetic acid). ${ }^{11}$

Nitration of dibenzothiophene by $\mathrm{NO}_{2}$. The reaction between aromatics and $\mathrm{N}_{2} \mathrm{O}_{4}$ has been shown ${ }^{12}$ to pro- 
Table 1. Overview of yields of products from the photolysis of dibenzothiophene (2) $\left(0.34 \mathrm{~mol} \mathrm{dm}^{-3}\right)$ and tetranitromethane $\left(0.68 \mathrm{~mol} \mathrm{dm}^{-3}\right)$.

\begin{tabular}{|c|c|c|c|c|c|c|c|c|c|}
\hline \multirow[b]{2}{*}{$t / \mathrm{h}$} & \multirow[b]{2}{*}{ Conversion (\%) } & \multicolumn{8}{|c|}{ Yield $(\%)$} \\
\hline & & 3 & 4 & 9 & $\begin{array}{l}\text { Unidentified } \\
\text { aromatics }\end{array}$ & 5 & 6 & 7 & $\begin{array}{l}\text { Unidentified } \\
\text { adducts }\end{array}$ \\
\hline \multicolumn{10}{|c|}{ In dichloromethane at $20^{\circ} \mathrm{C}$} \\
\hline $\begin{array}{l}2 \\
4 \\
5\end{array}$ & $\begin{array}{l}48 \\
69 \\
79\end{array}$ & $\begin{array}{l}58.3 \\
57.1 \\
56.4\end{array}$ & $\begin{array}{r}9.8 \\
9.9 \\
11.1\end{array}$ & $\bar{z}$ & $\begin{array}{l}10.3 \\
11.8 \\
12.2\end{array}$ & $\begin{array}{l}4.7 \\
4.5 \\
4.1\end{array}$ & $\begin{array}{l}2.3 \\
1.7 \\
1.3\end{array}$ & $\begin{array}{l}4.8 \\
4.8 \\
3.9\end{array}$ & $\begin{array}{r}9.8 \\
10.2 \\
11.1\end{array}$ \\
\hline \multicolumn{10}{|c|}{ In dichloromethane at $-20^{\circ} \mathrm{C}$} \\
\hline $\begin{array}{l}1 \\
3 \\
5\end{array}$ & $\begin{array}{l}20 \\
45 \\
62\end{array}$ & $\begin{array}{l}51.1 \\
54.0 \\
58.5\end{array}$ & $\begin{array}{l}7.4 \\
7.6 \\
7.6\end{array}$ & $\begin{array}{l}- \\
-\end{array}$ & $\begin{array}{l}17.8 \\
18.2 \\
15.6\end{array}$ & $\begin{array}{l}5.3 \\
4.5 \\
4.2\end{array}$ & $\begin{array}{l}2.6 \\
1.9 \\
1.5\end{array}$ & $\begin{array}{l}5.3 \\
4.9 \\
4.4\end{array}$ & $\begin{array}{r}10.5 \\
8.9 \\
8.2\end{array}$ \\
\hline \multicolumn{10}{|c|}{ In acetonitrile at $20^{\circ} \mathrm{C}$} \\
\hline $\begin{array}{l}1 \\
3 \\
5\end{array}$ & $\begin{array}{l}29 \\
72 \\
85\end{array}$ & $\begin{array}{l}67.6 \\
66.8 \\
74.2\end{array}$ & $\begin{array}{l}23.8 \\
23.1 \\
15.2\end{array}$ & $\begin{array}{l}7.6 \\
7.5 \\
8.3\end{array}$ & $\begin{array}{l}1.0 \\
2.6 \\
2.3\end{array}$ & $\begin{array}{l}- \\
-\end{array}$ & $\begin{array}{l}- \\
-\end{array}$ & $\begin{array}{l}- \\
-\end{array}$ & $\overline{-}$ \\
\hline \multicolumn{10}{|c|}{ In $1,1,1,3,3,3$-hexafluoropropan-2-ol at $20^{\circ} \mathrm{C}$} \\
\hline $\begin{array}{l}1 \\
3 \\
5\end{array}$ & $\begin{array}{l}37 \\
72 \\
85\end{array}$ & $\begin{array}{l}85.1 \\
85.0 \\
85.1\end{array}$ & $\begin{array}{l}12.2 \\
11.8 \\
12.6\end{array}$ & $\begin{array}{l}- \\
-\end{array}$ & $\begin{array}{l}2.7 \\
2.2 \\
2.3\end{array}$ & I & I & - & $\begin{array}{l}- \\
-\end{array}$ \\
\hline
\end{tabular}<smiles></smiles>

3<smiles>O=[N+]([O-])c1ccc2sc3ccccc3c2c1</smiles>

4<smiles>O=[N+]([O-])[C@H]1C=C[C@@H](O)c2c1sc1ccccc21</smiles>

5<smiles>O=[N+]([O-])c1cccc2sc3ccccc3c12</smiles>

8<smiles>O=[N+]([O-])c1cccc2c1sc1ccccc12</smiles>

ceed according to an electron-transfer mechanism, driven by the tendency of ArH to form a charge-transfer complex with $\mathrm{NO}^{+}$which is the active one-electron oxidant in the system [eqns. (5)-(8)].

$$
\begin{aligned}
& \mathrm{N}_{2} \mathrm{O}_{4} \rightleftharpoons 2 \mathrm{NO}_{2} \rightleftharpoons \mathrm{ON}-\mathrm{O}-\mathrm{NO}_{2} \\
& \mathrm{ON}-\mathrm{O}-\mathrm{NO}_{2}+\mathrm{ArH} \rightleftharpoons \mathrm{ArH} \cdots \mathrm{NO}^{+} \mathrm{NO}_{3}{ }^{-} \\
& \mathrm{ArH} \cdots \mathrm{NO}^{+} \rightleftharpoons \mathrm{ArH} \\
&
\end{aligned}
$$

Thus the radical cation $\mathrm{ArH}^{+}$will be generated in the presence of the neutral radical $\mathrm{NO}_{2}$, allowing for the characteristics of the coupling process to be studied. The nitrous acid catalyzed (NAC) nitration of aromatics by dilute nitric acid follows the same type of mechanism. ${ }^{13}$
The treatment of dibenzothiophene with $\mathrm{N}_{2} \mathrm{O}_{4}$ in dichloromethane for $72 \mathrm{~h}$ gave a $70 \%$ yield of dibenzothiophene sulfoxide 3 and a $27 \%$ yield of nitrodibenzothiophenes $(1-, 3 \% ; 2-, 81 \% ; 3-, 1 \% ; 4-, 16 \%)$. Essentially the same distribution of nitro isomers (total yield $50 \%$ ) was found in the nitrous acid catalyzed nitration by nitric acid in acetic acid: $1-, 2 \% ; 2-, 81 \% ; 3-, 1 \% ; 4-$, $16 \%$. Here the yield of 3 was $50 \%$.

A control experiment under conditions for which nitration by $\mathrm{NO}_{2}{ }^{+}$is known ${ }^{2 \mathrm{a}, 14}$ to dominate was performed by treatment of 2 with nitric acid in the presence of azide ion to scavenge any $\mathrm{HNO}_{2}$ present. These conditions gave a $17 \%$ yield of $\mathbf{3}$ and nitro-isomers in $41 \%$ yield: $1-, 3 \% ; 2-, 65 \% ; 3-, 2 \% ; 4-, 31 \%$. An experiment in which 2 was treated with nitronium tetrafluoroborate gave a nitro isomer distribution of: $1-, 2 \% ; 2-$, 


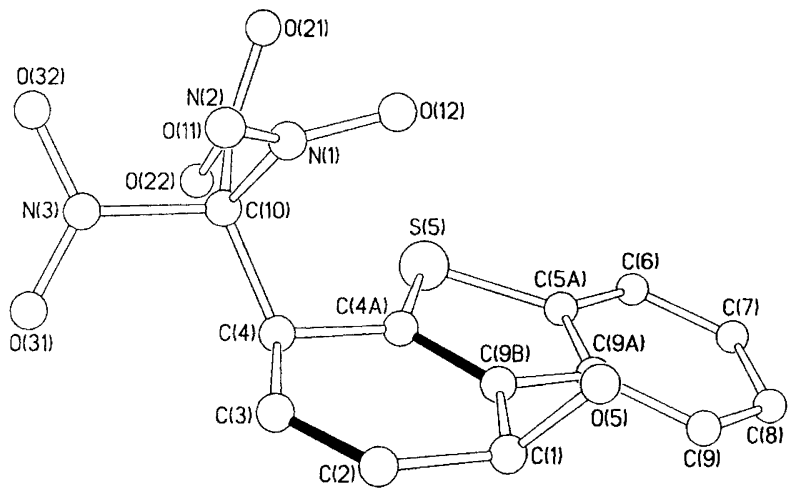

Fig. 2. Perspective drawing of molecule 1, compound 5. Double bonds are shown in black.

$79 \% ; 3-, 1 \%$ and $4-, 17 \%$, with a ratio $\geqslant 5$ of nitro compounds over sulfoxide 3 .

EPR spectral detection of $2^{\cdot+}$ in the photochemical reaction between 2 and tetranitromethane. The EPR spectral monitoring of the radical cation $\mathrm{ArH}^{+}$as generated through eqn. (1) is often possible, especially if the nucleophilic reactivity of trinitromethanide ion has been curtailed, for example by protonation or strong solvation, as in HFP, or both. ${ }^{8}$ The radical cation of dibenzothiophene $2^{+}$has been generated from 2 by other oxidants and studied by EPR spectroscopy in HFP at room temperature, where it gives rise to a moderately well resolved spectrum of seven broad lines with a splitting of $0.17-0.18 \mathrm{mT}$. We therefore used this solvent for a study of the 2-tetranitromethane reaction.

Irradiation of the yellow-red solution of 2 (ca. $20 \mathrm{mmol}$ $\left.\mathrm{dm}^{-3}\right)$ and tetranitromethane $\left(0.6 \mathrm{~mol} \mathrm{dm}^{-3}\right)$ by light of $\lambda>430 \mathrm{~nm}$ for $6 \mathrm{~min}$ with accumulation of spectra gave a weak, broad singlet $\left(\Delta H_{\mathrm{pp}} \approx 0.4 \mathrm{mT}\right)$; in the presence

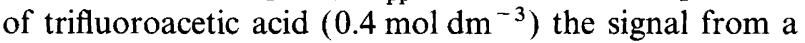
similar solution increased in intensity by a factor of 50 , but still remained a broad, featureless signal of $\Delta H_{\mathrm{pp}}=$ $0.32 \mathrm{mT}$. The lack of resolution was probably due to exchange processes and might possibly be avoidable at lower concentrations. Similar irradiation of a faintly yellow solution of $2\left(5 \mathrm{mmol} \mathrm{dm}{ }^{-3}\right)$, tetranitromethane $\left(0.05 \mathrm{~mol} \mathrm{dm}^{-3}\right)$ and trifluoroacetic acid $\left(0.2 \mathrm{~mol} \mathrm{dm}^{-3}\right)$ gave rise to the EPR spectrum shown in Fig. 3a. A forward-back Fourier transform removed the low-frequency component (Fig. 3b); the splittings are all $0.17-0.18 \mathrm{mT}$ and identical to those of the spectrum earlier ${ }^{4}$ assigned to $2^{+}$. Upon discontinuation of the irradiation, the signal disappeared within minutes.

\section{Discussion}

A problem: formation of sulfoxide 3 . The formation of 3 represents a point of ambiguity in any oxidative or electrophilic reaction of $\mathbf{2}$, since it is not always clear that this regiochemical outcome has any diagnostic value. If we consider nitration as an example, the electrophilic
Table 2. Fractional coordinates for atoms in $r$-1-hydroxy-c-4trinitromethyl-1,4-dihydrodibenzothiophene (5). ${ }^{a}$

\begin{tabular}{lrrrr}
\hline Atom & $10^{4} X / a$ & $10^{4} Y / b$ & $10^{4} Z / C$ & $10^{3} U / \AA^{2}$ \\
\hline Molecule 1 & & & & \\
$S(5)$ & $2581(1)$ & $2653(1)$ & $3958(1)$ & $31(1)$ \\
$O(11)$ & $4367(1)$ & $5355(2)$ & $5691(2)$ & $88(1)$ \\
$O(12)$ & $4069(1)$ & $3852(2)$ & $5016(2)$ & $64(1)$ \\
$O(21)$ & $3169(1)$ & $4759(2)$ & $3510(2)$ & $74(1)$ \\
$O(22)$ & $2444(1)$ & $4907(2)$ & $3556(1)$ & $65(1)$ \\
$O(31)$ & $3202(1)$ & $6372(2)$ & $5416(2)$ & $50(1)$ \\
$O(32)$ & $3405(1)$ & $6700(2)$ & $4579(2)$ & $87(1)$ \\
$O(5)$ & $4445(1)$ & $2074(2)$ & $6695(1)$ & $37(1)$ \\
$N(1)$ & $3996(1)$ & $4707(2)$ & $5206(2)$ & $51(1)$ \\
$N(2)$ & $2962(2)$ & $4846(2)$ & $3872(2)$ & $50(1)$ \\
$N(3)$ & $3328(1)$ & $6111(2)$ & $4975(2)$ & $44(1)$ \\
$C(1)$ & $3907(1)$ & $2429(2)$ & $6510(2)$ & $28(1)$ \\
$C(2)$ & $3973(1)$ & $3550(2)$ & $6767(2)$ & $32(1)$ \\
$C(3)$ & $3665(1)$ & $4330(2)$ & $6242(2)$ & $31(1)$ \\
$C(4)$ & $3201(1)$ & $4224(2)$ & $5279(2)$ & $24(1)$ \\
$C(4 A)$ & $3118(1)$ & $3079(2)$ & $5015(2)$ & $23(1)$ \\
$C(5 A)$ & $2766(1)$ & $1348(2)$ & $4281(2)$ & $29(1)$ \\
$C(6)$ & $2512(1)$ & $460(2)$ & $3752(2)$ & $38(1)$ \\
$C(7)$ & $2690(1)$ & $-513(2)$ & $4142(2)$ & $47(1)$ \\
$C(8)$ & $3110(1)$ & $-610(2)$ & $5030(2)$ & $45(1)$ \\
$C(9)$ & $3370(1)$ & $261(2)$ & $5546(2)$ & $37(1)$ \\
$C(9 A)$ & $3208(1)$ & $1262(2)$ & $5171(2)$ & $26(1)$ \\
$C(9 B)$ & $3415(1)$ & $2281(2)$ & $5575(2)$ & $22(1)$ \\
$C(10)$ & $3369(1)$ & $4932(2)$ & $4848(2)$ & $30(1)$ \\
& & & &
\end{tabular}

Molecule 2

\begin{tabular}{lrrrr}
$S\left(5^{\prime}\right)$ & $1332(1)$ & $5336(1)$ & $1476(1)$ & $34(1)$ \\
$O\left(11^{\prime}\right)$ & $599(1)$ & $8291(2)$ & $2664(1)$ & $50(1)$ \\
$O\left(12^{\prime}\right)$ & $836(1)$ & $6638(2)$ & $2811(1)$ & $54(1)$ \\
$O\left(21^{\prime}\right)$ & $1884(1)$ & $7163(2)$ & $3209(1)$ & $56(1)$ \\
$O\left(22^{\prime}\right)$ & $1761(1)$ & $7531(2)$ & $2044(2)$ & $53(1)$ \\
$O\left(31^{\prime}\right)$ & $506(1)$ & $9111(2)$ & $1021(1)$ & $43(1)$ \\
$O\left(32^{\prime}\right)$ & $1287(1)$ & $9363(2)$ & $2349(1)$ & $45(1)$ \\
$O\left(5^{\prime}\right)$ & $-237(1)$ & $4948(1)$ & $1654(1)$ & $37(1)$ \\
$N\left(1^{\prime}\right)$ & $783(1)$ & $7519(2)$ & $2541(1)$ & $37(1)$ \\
$N\left(2^{\prime}\right)$ & $1591(1)$ & $7413(2)$ & $2458(2)$ & $38(1)$ \\
$N\left(3^{\prime}\right)$ & $901(1)$ & $8823(2)$ & $1746(2)$ & $33(1)$ \\
$C\left(1^{\prime}\right)$ & $-248(1)$ & $5247(2)$ & $950(2)$ & $26(1)$ \\
$C\left(2^{\prime}\right)$ & $-422(1)$ & $6367(2)$ & $733(2)$ & $29(1)$ \\
$C\left(3^{\prime}\right)$ & $-93(1)$ & $7125(2)$ & $788(2)$ & $28(1)$ \\
$C\left(4^{\prime}\right)$ & $537(1)$ & $6965(2)$ & $1133(2)$ & $25(1)$ \\
$C\left(4 A^{\prime}\right)$ & $688(1)$ & $5815(2)$ & $1258(2)$ & $25(1)$ \\
$C\left(5 A^{\prime}\right)$ & $1118(1)$ & $4052(2)$ & $1448(2)$ & $33(1)$ \\
$C\left(6^{\prime}\right)$ & $1431(1)$ & $3135(2)$ & $1579(2)$ & $42(1)$ \\
$C\left(7^{\prime}\right)$ & $1173(2)$ & $2187(2)$ & $1482(2)$ & $47(1)$ \\
$C\left(8^{\prime}\right)$ & $608(2)$ & $2123(2)$ & $1241(2)$ & $41(1)$ \\
$C\left(9^{\prime}\right)$ & $314(1)$ & $3019(2)$ & $1141(2)$ & $35(1)$ \\
$C\left(9 A^{\prime}\right)$ & $562(1)$ & $4006(2)$ & $1241(2)$ & $27(1)$ \\
$C\left(9 B^{\prime}\right)$ & $334(1)$ & $5045(2)$ & $1155(2)$ & $24(1)$ \\
$C\left(10^{\prime}\right)$ & $939(1)$ & $7636(2)$ & $1949(2)$ & $27(1)$ \\
\hline
\end{tabular}

${ }^{a}$ The equivalent isotropic temperature factor is defined as one-third of orthogonalized $U_{i j}$ tensor $\left(\AA^{2}\right)$.

attack of $\mathrm{NO}_{2}{ }^{+}$upon the sulfur atom of 2 will lead to the same intermediate $\mathbf{1 0}$ as from similar $\mathrm{NO}_{2}$ attack upon $\mathbf{2}^{+}$in the NAC nitration mechanism (Scheme 1). The common intermediate cation $\mathbf{1 0}$ will give 3 by loss of $\mathrm{NO}^{+}$, as found earlier for the reaction between $\mathrm{NO}_{2}{ }^{+}$ and dialkyl sulfides ${ }^{15}$ or $\mathrm{NO}_{2}$ and radical cations of dialkyl sulfides. ${ }^{16}$ This is of no consequence for the NAC 


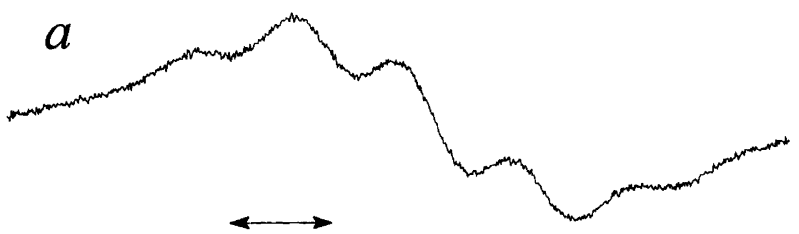

$0.16 \mathrm{mT}$

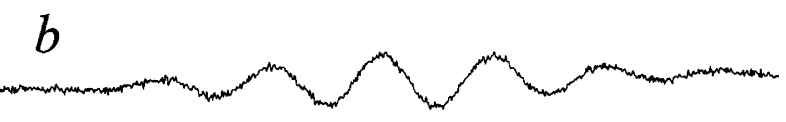

Fig. 3.( a) EPR spectrum from an irradiated solution (light of wavelength $>430 \mathrm{~nm})$ of $2\left(5 \mathrm{mmol} \mathrm{dm}{ }^{-3}\right)$, tetranitromethane $\left(50 \mathrm{mmol} \mathrm{dm}^{-3}\right)$ and trifluoroacetic acid $\left(0.2 \mathrm{~mol} \mathrm{dm}^{-3}\right)$. (b) The same spectrum after a forward-back Fourier transform.

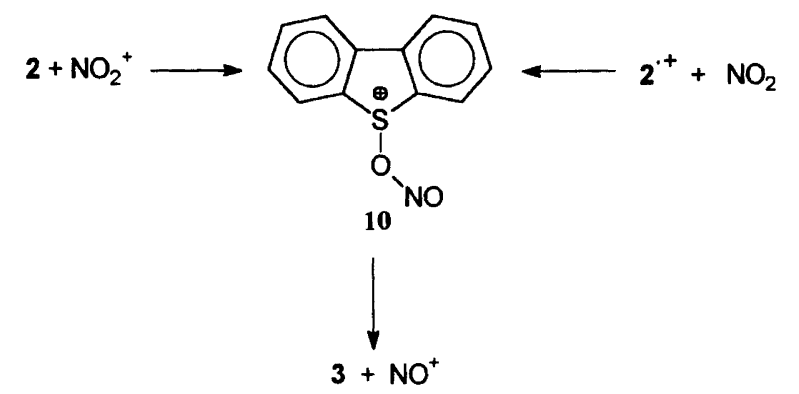

Scheme 1.

mechanism, but is important for judging results of $\mathrm{NO}_{2}{ }^{+}$ nitration, since the $\mathrm{NO}^{+}$formed can cause diversion to the NAC mechanism. Truly, scavengers of $\mathrm{NO}^{+}$can be added, but their efficiency is not perfect.

Earlier results from the treatment of 2 by nitric acid produced only its sulfoxide $\mathbf{3}$, whereas with nitric acidacetic anhydride 2-nitrodibenzothiophene $(40 \%)$ and sulfoxide $3(40 \%)$ were formed. ${ }^{17}$

Nitration of 2 by $\mathrm{NO}_{2}$. The regiochemistry of this process should be governed by the coupling of $2^{+}$and $\mathrm{NO}_{2}$ and thus by the spin densities at the various positions of $2^{+}$, as theoretically calculated ${ }^{1}$ and shown below.

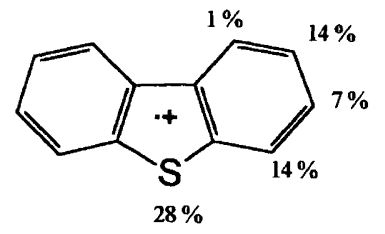

The isomer distributions of the $2-\mathrm{N}_{2} \mathrm{O}_{4}$ reaction in dichloromethane and the NAC-catalyzed nitration of $\mathbf{2}$ are in agreement with the theoretical calculations: Predominant attack at sulfur, giving intermediate $\mathbf{1 0}$ (Scheme 1) and eventually sulfoxide 3 by loss of $\mathrm{NO}^{+}$, next in order followed by attack at $\mathrm{C} 2$ and less at $\mathrm{C} 4$, practically no attack at $\mathrm{C} 1$ and $\mathrm{C} 3$.

It should be noted that electrophilic attack of $\mathrm{NO}_{2}{ }^{+}$ upon neutral 2 in the presence of a scavenger of nitrous acid gives a similar distribution of nitro isomers but yields significantly smaller amounts of sulfoxide 3 . The incursion of the NAC mechanism may be partly responsible for the formation of $\mathbf{3}$ in view of its high efficiency.

Oxidative acetoxylation of 2 . The interaction between $\mathbf{2}^{+}$and a nucleophile was predicted to occur predominantly at $\mathrm{C} 1$ and $\mathrm{C} 3$, with little attack at sulfur. The $\mathrm{Ag}^{\mathrm{II}}$ oxidation of 2 with acetate ion present most likely has the $2^{+}-\mathrm{AcO}^{-}$step as controlling the regiochemistry of acetoxylation. The isomer distribution of this reaction, attack at $\mathrm{C} 153 \%, \mathrm{C} 2 \leqslant 1 \%, \mathrm{C} 39 \%$ and $\mathrm{C} 437 \%$ and with no indication of attack at sulfur, does show some preponderance for attack at $\mathrm{C} 1+\mathrm{C} 3$ over $\mathrm{C} 2+\mathrm{C} 4$ and, in addition, the expected low probability of attack at sulfur. The low incidence of attack at C2 is predicted, whereas the relatively high percentage of 4-isomer is not. Presently there is no good explanation of this behaviour.

Photolysis of 2 with tetranitromethane in various solvents. The EPR spectral experiments with 2-tetranitromethane in HFP show that the initial photochemical step produces $\mathbf{2}^{+}$which in this particular case is reactive enough to be consumed rapidly as long as trinitromethanide ion is present, as shown previously for a wide range of radical cations under different conditions. Protonation of trinitromethanide ion removes this reactant, and thus the radical cation concentration increases strongly. ${ }^{8}$

The preparative photolyses of 2-tetranitromethane in dichloromethane were characterized by the formation of sulfoxide $3(50-60 \%)$ and 2-nitrodibenzothiophene 4 (ca. $10 \%$ ) and low yields of adducts 5-7 (total 12\% at low conversions). Of the adducts identified, adducts 5 and 7 (total $10 \%$ ) are formed by initial attack of trinitromethanide ion at $\mathrm{C} 4$ in the radical cation $2^{+}$. The remaining adduct 6 , yield ca. $2 \%$, is formed by initial attack of trinitromethanide ion at $\mathrm{Cl}$ in the radical cation $2^{+}$. Given the relatively large amounts of unidentified material, ca. $10 \%$ adducts and $10 \%$ aromatic compounds for the reaction at $20^{\circ} \mathrm{C}$, comment on these reactions of 2 must be limited, but one can distinguish at least the following important features.

The sulfoxide 3 was formed as the major product from the reaction between 2 and $\mathrm{NO}_{2}$ in dichloromethane, as shown above. In the photolysis of ArH with tetranitromethane, $\mathrm{NO}_{2}$ is formed in the initial photochemical step [eqn. (1)] and will reach a low, steady bulk concentration during the photolysis period, as earlier shown for the naphthalene-tetranitromethane system. ${ }^{18}$ Thus the sulfoxide 3 can be formed in the thermal reaction between 2 and $\mathrm{NO}_{2}$, in addition to the coupling between $\mathbf{2}^{+}$and $\mathrm{NO}_{2}$ (Scheme 1). The formation of the 2-nitro isomer 4 can be explained in a similar way. Thus if we maintain that the formation of $\mathbf{3}$ and $\mathbf{4}$ are manifestations of the $2^{+}-\mathrm{NO}_{2}$ pathway, the results are in agreement with predictions.

In the trinitromethyl containing products, 5-7, formed in a combined yield of $12 \%$, the centres of initial attack 
are $\mathrm{C} 4$ and $\mathrm{Cl}$ in a ratio of ca. $4: 1$, which is not in agreement with the predictions above for the $2^{+}-\mathrm{Nu}$ reaction. Given the uncertainty of the product composition noted above, it is not clear whether this discrepancy is real or not.

In both acetonitrile and HFP the yields of dibenzothiophene sulfoxide 3 were high (Table 1), reaching $85 \%$ for the HFP reaction. Adducts were not seen in reactions in HFP, not surprisingly given the known suppression of nucleophilic activity in that solvent. ${ }^{19}$ Thus we can safely assume that the predominant reaction taking place in HFP has the $2^{\cdot}-\mathrm{NO}_{2}$ step as controlling the regiochemistry, leading to $\mathbf{3}$ and 2-nitro isomer $\mathbf{4}$ as the products, in agreement with predictions.

In acetonitrile adducts were not detected among the products but perhaps significantly 4-nitrodibenzothiophene 9 was formed, a nitroarene not detected in HFP. In the light of the known lability of trinitromethyl derivatives in acetonitrile solution, ${ }^{20}$ it is conceivable that the 4-nitrodibenzothiophene $\mathbf{4}$ arises by decomposition of 4-trinitromethyl adducts such as 5 and 7 via the sequence 5 (7) $\rightarrow$ 4-trinitromethyldibenzothiophene $\rightarrow$ dibenzothiophene-4-carboxylic acid $\rightarrow$ 4. However, it is also possible that $\mathbf{4}$ might be formed via an adduct in which the initial trinitromethanide attachment was at $\mathrm{C} 3$.

Conclusions. From the above it is clear that dibenzothiophene 2 can be oxidized to its radical cation $2^{+}$under a variety of conditions, and that model reactions of $2^{+}$ with radicals and/or nucleophiles can be carried out in controllable manner with respect to substitution at ring carbons. The regiochemistry of the reaction of $2^{\cdot+}$ with a radical $\left(\mathrm{NO}_{2}\right)$ was in agreement with theoretical predictions, whereas its reactions with nucleophiles (acetate or trinitromethanide ion) only partially conformed to such predictions. This is presumably partly due to the ease by which the sulfur atom is attacked leading to sulfoxide $\mathbf{3}$, presumably also by mechanisms not directly related to the intermediacy of $2^{+}$.

\section{Experimental}

General. Melting points are uncorrected. Infrared spectra were recorded on a Perkin Elmer 1600 series FTIR spectrometer; ${ }^{1} \mathrm{H}$ and ${ }^{13} \mathrm{C}$ NMR spectra were recorded on a Varian Unity 300 spectrometer with $\mathrm{SiMe}_{4}$ as an internal standard or a Bruker DRX $400 \mathrm{MHz}$ instrument. EPR spectra were recorded as published. ${ }^{8}$ HPLC separations were carried out on a Varian 5000 liquid chromatograph equipped with an Alltech cyanopropyl column, and using a Varian UV-50 ultraviolet spectrometric detector and hexane-dichloromethane as solvent mixtures. The GLC instrument (HP-5890 series II) was equipped with a fused silica column ( $25 \mathrm{~m}, \mathrm{OV}-1701)$. Separations by the Chromatotron have been described earlier. ${ }^{21}$ Tetranitromethane, dibenzothiophene and dibenzothiophene-5,5-dioxide were purchased from Aldrich. TMEDA was of Merck quality ( $>99 \%$ ) and butyl- lithium was from Aldrich $\left(2.5 \mathrm{~mol} \mathrm{dm}^{-3}\right.$ in hexane). Diethyl ether (Merck GR dried, $<0.0075 \%$ water) was passed through alumina prior to use. Dichloromethane (AR) and acetonitrile (HiPerSolv) were from BDH and 1,1,1,3,3,3-hexafluoropropan-2-ol from Sigma or Merck (Uvasol ${ }^{\circledR}$ quality).

WARNING. While we did not experience any incidents in working with tetranitromethane, it should be noted that its mixtures with hydrocarbons are detonative within certain concentration limits, and that due care should be taken in handling mixtures of tetranitromethane and organic molecules. ${ }^{22}$

\section{Preparation and purification of acetoxydibenzothiophenes}

l-Acetoxydibenzothiophene. This isomer was obtained in pure form from the $\mathrm{Ag}$ (II) mediated acetoxylation of 2 (below). MS: $m / z$ (rel. int.) 242(22), 201 (14), 200(100), 172(14), 171(32). ${ }^{1} \mathrm{H}$ NMR $\left(\mathrm{CDCl}_{3}\right): \delta 7.25(\mathrm{H} 2), 7.48$ (H3), 7.75 (H4), 7.86 (H6), 7.48 (H7), 7.48 (H8), 8.27 (H9), $2.55\left(\mathrm{CH}_{3}\right), J_{23} 8.0 \mathrm{~Hz}, J_{24} 0.9 \mathrm{~Hz}, J_{34} 7.9 \mathrm{~Hz}$.

2-Acetoxydibenzothiophene. 2-Hydroxydibenzothiophene was prepared via treatment of 2-bromodibenzothiophene ${ }^{1-}$ with 1.1 equiv. of BuLi in diethyl ether for $1 \mathrm{~h}$, followed by bubbling with dioxygen for $6 \mathrm{~h} .{ }^{23}$ Treatment with a large excess of acetyl chloride gave 2-acetoxydibenzothiophene. MS: $m / z$ (rel. int.) 242(19), 201(14), 200(100), 171(24). ${ }^{1} \mathrm{H}$ NMR $\left(\mathrm{CDCl}_{3}\right): \delta 7.88(\mathrm{H1}), 7.20$ (H3), 7.84 (H4), 7.86 (H6), 7.47 ( $\mathrm{H} 7$ and $\mathrm{H} 8), 8.10$ (H9), $2.38\left(\mathrm{CH}_{3}\right), J_{13} 1.3 \mathrm{~Hz}, J_{34} 8.6 \mathrm{~Hz}$.

3-Acetoxydibenzothiophene. This isomer was obtained in pure form from the $\mathrm{Ag}^{\mathrm{II}}$-mediated acetoxylation of $\mathbf{2}$ (below). MS: $m / z$ (rel. int.) 242(17), 201(14), 200(100), 172(14), 171(33). ${ }^{1} \mathrm{H}$ NMR $\left(\mathrm{CDCl}_{3}\right): \delta 8.05(\mathrm{H1}), 7.30$ $(\mathrm{H} 2), 7.48(\mathrm{H} 4), 2.44\left(\mathrm{CH}_{3}\right), J_{12} 8.2 \mathrm{~Hz}, J_{14}$ and $J_{24}$ $0.9 \mathrm{~Hz}$.

4-Acetoxydibenzothiophene. 4-Hydroxydibenzothiophene was prepared via direct lithiation of dibenzothiophene with 2 equival. of BuLi in diethyl ether for $2 \mathrm{~h}$, followed by bubbling with dioxygen for $6 \mathrm{~h} .^{22}$ Treatment with a large excess of acetyl chloride gave 4-acetoxydibenzothiophene. MS: $m / z$ (rel. int.) 242(19), 201(13), 200(100), 172(13), 171(31). ${ }^{1} \mathrm{H}$ NMR $\left(\mathrm{CDCl}_{3}\right): 8.04(\mathrm{H1}), 7.48$ (H2), $7.21(\mathrm{H} 3), 7.85(\mathrm{H} 6)$, c. $7.45(\mathrm{H} 7$ and $\mathrm{H} 8), 8.16$ (H9), $2.44\left(\mathrm{CH}_{3}\right), J_{12} 7.8 \mathrm{~Hz}, J_{13} 1.0 \mathrm{~Hz}, J_{23} 7.9 \mathrm{~Hz}$.

Preparation and purification of nitrodibenzothiophenes. 1Nitro- and 3-nitrodibenzothiophene were obtained in low overall yield via nitration of dibenzothiophene-5,5dioxide $^{24}$ followed by reduction of the resulting mixture of 1- and 3-nitrodibenzothiophene sulfone with lithium aluminum hydride in diethyl ether. ${ }^{25}$ Separation and purification was performed on the Chromatotron (hexane-dichloromethane $10: 1$, elution order 1-, 3-).

2-Nitro- and 4-nitrodibenzothiophene were obtained from Chromatotron purification (hexane-dichlorometh- 
ane $10: 1$, elution order 2-, 4-) of the isomer mixture obtained from the nitrous acid catalyzed nitration $(65 \%$ nitric acid) described below.

1-Nitrodibenzothiophene (8). MS: $m / z$ (rel. int.): 230(11), 229(100), 199(10), 184(11), 183(80). ${ }^{1} \mathrm{H} \quad \mathrm{NMR}$ $\left(\mathrm{CDCl}_{3}\right): \delta 8.06(\mathrm{H} 2), 7.55(\mathrm{H} 3), 7.78(\mathrm{H} 4), 7.91(\mathrm{H} 6)$, 7.48 (H7 and H8), $8.12(\mathrm{H} 9), J_{24} 1.02 \mathrm{~Hz}, J_{23} 8.01 \mathrm{~Hz}$, $J_{34} 7.72 \mathrm{~Hz}$.

2-Nitrodibenzothiophene (4). MS: $m / z$ (rel. int.): 230(12), 229 (100), 199(14), 184(9), 183(63). ${ }^{1} \mathrm{H}$ NMR $\left(\mathrm{CDCl}_{3}\right)$ : $\delta 9.02$ (H1), 8.32 (H3), 7.97 (H4), 7.97 (or 7.90) (H6), 7.57 (H7 and $\mathrm{H} 8$ ), 7.90 (or 7.97) (H9), $J_{13} 2.20 \mathrm{~Hz}$, $J_{34} 8.80 \mathrm{~Hz}$.

3-Nitrodibenzothiophene. MS: $m / z$ (rel. int.) 230(14), 229(100), 199(11), 184(9), 183(69). ${ }^{1} \mathrm{H}$ NMR $\left(\mathrm{CDCl}_{3}\right)$ :

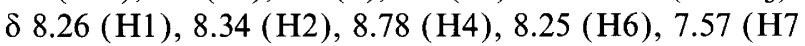
and $\mathrm{H} 8$ ), 7.93 (H9), $J_{12} 8.71 \mathrm{~Hz}, J_{24} 2.06 \mathrm{~Hz}, J_{14} 0.36 \mathrm{~Hz}$.

4-Nitrodibenzothiophene (9). MS: $m / z$ (rel. int.) 230 (16), 229 (100), 213(8), 199(8), 184(11), 183(67). ${ }^{1} \mathrm{H}$ NMR $\left(\mathrm{CDCl}_{3}\right): \delta 8.50(\mathrm{H} 1), 7.65(\mathrm{H} 2), 8.52(\mathrm{H} 3), 8.22(\mathrm{H} 6)$, $7.57(\mathrm{H} 7$ and $\mathrm{H} 8), 7.96(\mathrm{H} 9), J_{12}$ and $J_{23} 8.0 \mathrm{~Hz}, J_{13}$ $1.0 \mathrm{~Hz}$.

Photochemistry. The photochemical experiments were performed with filtered light (cut-off at $435 \mathrm{~nm}, 5 \mathrm{~cm}$ water IR filter, with a $300 \mathrm{~W}$ incandescent lamp) as described before. ${ }^{18}$ A solution of dibenzothiophene (2) $\left(500 \mathrm{mg}, 0.34 \mathrm{~mol} \mathrm{dm}^{-3}\right)$ and tetranitromethane $(0.68$ mol dm ${ }^{-3}$ ) in dichloromethane (at 20 or $-20^{\circ} \mathrm{C}$ ), acetonitrile (at $20^{\circ} \mathrm{C}$ ), or 1,1,1,3,3,3-hexafluoropropan-2-ol (at $20^{\circ} \mathrm{C}$ ) was irradiated and small samples were withdrawn for analysis at suitable intervals (Table 1). The work-up procedure, involving evaporation of solvent and excess tetranitromethane, was conducted at a temperature of $<0^{\circ} \mathrm{C}$. The crude product mixtures were stored at $-78^{\circ} \mathrm{C}$ and were analysed $\left({ }^{1} \mathrm{H}\right.$ NMR spectroscopy, see below) as soon as possible.

Photochemistry of dibenzothiophene (2) in dichloromethane at $20^{\circ} \mathrm{C}$ and the identification of products (3-7). Reaction of dibenzothiophene-tetranitromethane in dichloromethane at $20^{\circ} \mathrm{C}$, as above, for $5 \mathrm{~h}$ resulted in partial conversion (ca. 80\%) $\left({ }^{1} \mathrm{H}\right.$ NMR spectra) into 2-nitrodibenzothiophene (4) (11\%), $t$-2-nitro-r-1-trinitromethyl1,2-dihydrodibenzothiophene (6) (1\%), r-1-hydroxy-c-4trinitromethyl-1,4-dihydrodibenzothiophene (5) (4\%), $r$ 1 -nitro-c-4-trinitromethyl-1,4-dihydrodibenzothiophene (7) (4\%), dibenzothiophene sulfoxide (3) (56\%), unidentified adducts (total 11\%), and unidentified aromatic compounds (total 12\%). These products were separated partially by HPLC on a cyanopropyl column using hexane-dichloromethane mixtures as the eluting solvents. The compound eluted are treated in order below.

The first material eluted was a complex mixture of 2nitrodibenzothiophene $\mathbf{4}$ and a number of other aromatic compounds. A pure sample of $\mathbf{4}$, obtained by chromatography of this mixture on a silica gel Chromatotron plate, was identical with authentic material.

The first adduct eluted from the HPLC column was obtained only as an impure oil, and identified as $t$-2-nitro-r-1-trinitromethyl-1,2-dihydrodibenzothiophene (6) from its spectroscopic data and a consideration of its mode of formation. The connectivity in the nitrotrinitromethyl adduct 6 was established from the results of nuclear Overhauser experiments (NOE) and reversedetected heteronuclear correlation spectra (HMQC). In particular, the $\mathrm{CH}-\mathrm{C}\left(\mathrm{NO}_{2}\right)_{3}$ structural feature was located at $\mathrm{C} 1\left({ }^{13} \mathrm{C}\right.$ NMR $\delta 40.0,{ }^{1} \mathrm{H}$ NMR $\left.\delta 6.32\right)$ and the $\mathrm{CH}-\mathrm{NO}_{2}$ structural feature at $\mathrm{C} 2\left({ }^{13} \mathrm{C}\right.$ NMR $\delta 76.7,{ }^{1} \mathrm{H}$ NMR $\delta$ 5.77). The trans-stereochemistry of the nitrotrinitromethyl adduct 6 was assigned on the basis of the known steric effect of the bulky trinitromethyl group on the stereochemistry of the radical coupling of nitrogen dioxide with the delocalized carbon radical in the second addition step in the formation of such 1,2-adducts. ${ }^{5,26}$

t-2-Nitro-r-1-trinitromethyl-1,2-dihydrodibenzothiophene (6). Eluted as an oil containing impurities (ca. 10\%). ${ }^{1} \mathrm{H}$ NMR $\left(\mathrm{CDCl}_{3}\right) \delta 5.77\left(\right.$ br d, $\left.J_{\mathrm{H} 2, \mathrm{H} 3} 6.8 \mathrm{~Hz}, \mathrm{H} 2\right), 6.15$ (br dd, $J_{\mathrm{H} 3, \mathrm{H} 4} 9.7 \mathrm{~Hz}, J_{\mathrm{H} 3, \mathrm{H} 2} 6.8 \mathrm{~Hz}, \mathrm{H} 3$ ), 6.32 (br s, H1), $6.95\left(\mathrm{~d}, J_{\mathrm{H} 4, \mathrm{H} 3} 9.7 \mathrm{~Hz}, \mathrm{H} 4\right)$; the remainder of the spectrum was obscured by signals from impurities. Nuclear Overhauser experiments gave the following results: irradiation at $\delta 5.77$ gave enhancements at $\delta 6.15(2.8 \%)$ and at $\delta 6.32(2.4 \%)$; irradiation at $\delta 6.15$ gave enhancements at $\delta 5.77(5.4 \%)$ and at $\delta 6.95(4.7 \%)$; irradiation at $\delta$ 6.32 gave enhancements at $\delta 5.77(3.3 \%)$ and at $\delta 7.70$ $(2.8 \%) .{ }^{13} \mathrm{C} \mathrm{NMR}\left(\mathrm{CDCl}_{3}\right) \delta 40.0(\mathrm{Cl}), 76.7(\mathrm{C} 2), 117.7$ (C3), 129.1 (C4) were located by reverse detected heteronuclear correlation experiments (HMQC).

r - 1-Hydroxy - c - 4 - trinitromethyl-1,4-dihydrodibenzothiophene (5). M.p. $97-100{ }^{\circ} \mathrm{C}$ (X-ray crystal structure determined, see below). IR: $v_{\max }\left(\mathrm{CHCl}_{3}\right)$ 3585, 1602, $1581 \mathrm{~cm}^{-1} .{ }^{1} \mathrm{H}$ NMR $\left(\mathrm{CDCl}_{3}\right) \delta 5.41\left(\mathrm{dd}, J_{\mathrm{H} 1, \mathrm{H} 2} 4.4 \mathrm{~Hz}\right.$, $\left.J_{\mathrm{H} 1, \mathrm{H} 4} 3.9 \mathrm{~Hz}, \mathrm{H} 1\right), 5.49\left(\mathrm{dd}, J_{\mathrm{H} 4, \mathrm{H} 1} 3.9 \mathrm{~Hz}, J_{\mathrm{H} 4, \mathrm{H} 3} 3.9 \mathrm{~Hz}\right.$, $\mathrm{H} 4), 6.18\left(\mathrm{dd}, J_{\mathrm{H} 3, \mathrm{H} 2} 9.8 \mathrm{~Hz}, J_{\mathrm{H} 3, \mathrm{H} 4} 3.9 \mathrm{~Hz}, \mathrm{H} 3\right), 6.67$ (dd, $\left.J_{\mathrm{H} 2, \mathrm{H} 3} 9.8 \mathrm{~Hz}, J_{\mathrm{H} 2, \mathrm{H} 1} 4.4 \mathrm{~Hz}, \mathrm{H} 2\right), 8.04$ (m, H9), 7.83 (m, H6), 7.46 (m, H7, H8); the assignments above were confirmed by double irradiation experiments. Nuclear Overhauser experiments gave the following results: irradiation at $\delta 5.41$ gave enhancements at $\delta 6.67(4.1 \%)$ and at $\delta 8.04(3.4 \%)$; irradiation at $\delta 5.49$ gave an enhancement at $\delta 6.18(1.8 \%)$; irradiation at $\delta 6.18$ gave enhancements at $\delta 5.49(3.9 \%)$ and at $\delta 6.67(5.3 \%)$; irradiation at $\delta 6.67$ gave enhancements at $\delta 5.41(4.0 \%)$ and at $\delta$ $6.18(6.6 \%) .{ }^{13} \mathrm{C} \mathrm{NMR}\left(\mathrm{CDCl}_{3}\right) \delta 43.3(\mathrm{C} 4), 61.0(\mathrm{C} 1)$, 120.9 (C3), 121.7 (C6), 122.8 (C9), 125.8 (C7, C8), 137.1 (C2), the remainder of the spectrum was obscured. The above correlations were confirmed by reverse-detected heteronuclear correlation spectra (HMQC, HMBC).

The crystal structure consists of two crystallographically independent molecules. The conformational 
differences between the two molecules, which lie substantially in the orientations of the nitro groups in the trinitromethyl function, are illustrated in Fig. 4 and are not significant chemically. In each molecule the cyclohexadiene ring is close to planar, but with a minor deviation towards a boat conformation with the $\mathrm{C}(4)-\mathrm{C}\left(\mathrm{NO}_{2}\right)_{3}$ and $\mathrm{C}(1)-\mathrm{OH}$ bonds in flagpole orientations; in such a conformation the steric interactions between the trinitromethyl and hydroxyl functions and the rest of the molecule would be relieved somewhat. The spectroscopic data for the hydroxy-trinitromethyl adduct 5 were in accord with the established structure. In particular, the results of nuclear Overhauser experiments and heteronuclear correlation spectra (HMQC, HMBC) led to the assignment of ${ }^{13} \mathrm{C}$ NMR signals $\delta$ $43.4(\mathrm{C} 4)$ and $\delta 61.0(\mathrm{C} 1)$ consistent with the attachment of trinitromethyl and hydroxy functions at those positions.

r-1-Nitro-c-4-trinitromethyl-1,4-dihydrodibenzothiophene (7). The third adduct eluted from the HPLC column was isolated as an impure oil (10\% impurity) which could not be induced to crystallize. Its structure was assigned tentatively as $r$-1-nitro-c-4-trinitromethyl-1,4dihydrodibenzothiophene (7). The connectivity in the nitro trinitromethyl adduct (7) was established by the results of nuclear Overhauser experiments and heteronuclear correlation spectra (HMQC, HMBC) which allowed the assignment of the ${ }^{13} \mathrm{C}$ NMR signals $\delta 43.4$ (C4), $\delta 77.3(\mathrm{C} 1), \delta 125.4(\mathrm{C} 3)$ and $\delta 129.2(\mathrm{C} 2)$. The tentative assignment of the $r$-1-nitro- $c$-4-trinitromethyl stereochemistry to adduct 7 is based on the relatively late elution of this compound from the HPLC column and after the hydroxy trinitromethyl adduct $\mathbf{5}$; characteristically a $r$-1-nitro-c-4-trinitromethyl adduct is eluted from a cyanopropyl HPLC column by hexanedichloromethane mixtures later than the corresponding $r$-1-nitro-t-4-trinitromethyl adduct. ${ }^{8 \mathrm{c}}{ }^{1} \mathrm{H}$ NMR $\left(\mathrm{CDCl}_{3}\right)$ $\delta 5.68\left(\mathrm{~m}, J_{\mathrm{H} 4, \mathrm{H} 1} 4.4 \mathrm{~Hz}, J_{\mathrm{H} 4, \mathrm{H} 3} 3.9 \mathrm{~Hz}, J_{\mathrm{H} 4, \mathrm{H} 2} 1.5 \mathrm{~Hz}\right.$, $\mathrm{H} 4), 6.35$ (ddd, $J_{\mathrm{H} 1, \mathrm{H} 2} 4.9 \mathrm{~Hz}, J_{\mathrm{H} 1, \mathrm{H} 4} 4.4 \mathrm{~Hz}, J_{\mathrm{H} 1, \mathrm{H} 3} 1.0 \mathrm{~Hz}$, $\mathrm{H} 1), 6.54$ (ddd, $J_{\mathrm{H} 3, \mathrm{H} 2} 9.8 \mathrm{~Hz}, J_{\mathrm{H} 3, \mathrm{H} 4} 3.9 \mathrm{~Hz}, J_{\mathrm{H} 3, \mathrm{H} 1} 1.0 \mathrm{~Hz}$, $\mathrm{H} 3), 6.88\left(J_{\mathrm{H} 2, \mathrm{H} 3} 9.8 \mathrm{~Hz}, J_{\mathrm{H} 2, \mathrm{H} 1} 4.9 \mathrm{~Hz}, J_{\mathrm{H} 2, \mathrm{H} 4} 1.5 \mathrm{~Hz}, \mathrm{H} 2\right)$,

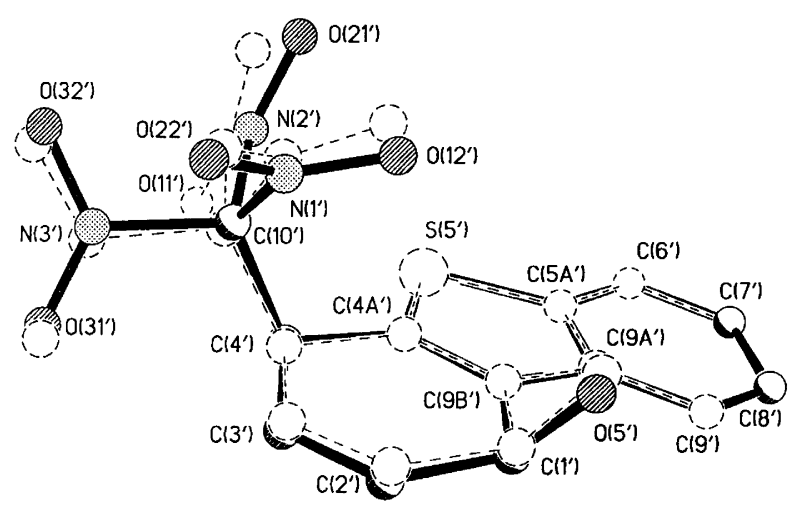

Fig. 4. Super-position of molecule 1 (broken lines) and molecule 2 (solid lines) of compound 5 . the remainder of the spectrum was obscured and the coupling constants given above were confirmed by double irradiation experiments. Nuclear Overhauser experiments gave the following results: irradiation at $\delta 5.68$ gave an enhancement at $\delta 6.54(2.3 \%)$; irradiation at $\delta 6.35$ gave enhancements at $\delta 6.88(6.3 \%)$ and at $\delta 7.78(2.1 \%)$; irradiation at $\delta 6.54$ gave enhancements at $\delta 5.68(5.3 \%)$ and at $\delta 6.88(5.6 \%)$; irradiation at $\delta 6.88$ gave enhancements at $\delta 6.35(4.3 \%)$ and at $\delta 6.54(4.5 \%) .{ }^{13} \mathrm{C}$ NMR $\left(\mathrm{CDCl}_{3}\right) \delta 43.3(\mathrm{C} 4), 77.3$ (C1), 125.4 (C3), 129.2 (C2) were located by reverse detected heteronuclear correlation spectra (HMQC).

Dibenzothiophene sulfoxide (3), eluted last in order, was identical with authentic material.

Photochemistry of dibenzothiophene (2) in acetonitrile at $20^{\circ} \mathrm{C}$. Reaction of 2 -tetranitromethane in acetonitrile at $20^{\circ} \mathrm{C}$, as above, for $5 \mathrm{~h}$ resulted in partial conversion (ca. 85\%) $\left({ }^{1} \mathrm{H}\right.$ NMR spectra) into dibenzothiophene sulfoxide (3) (74\%), 2-nitrobenzothiophene (4) (15\%), 4-nitrobenzothiophene (9) $(8 \%)$, and unidentified aromatic compounds (total $2 \%$ ) (Table 1 ).

Oxidative acetoxylation of $2 \mathrm{by} \mathrm{Ag}^{\mathrm{I}}$-peroxydisulfate in acetic acid. A mixture of $2(1.0 \mathrm{~g}, 5.4 \mathrm{mmol}), 2,2^{\prime}$ bipyridine $(100 \mathrm{mg}, 0.64 \mathrm{mmol})$, sodium peroxydisulfate $(1.5 \mathrm{~g}, 6.3 \mathrm{mmol})$ and silver tetrafluoroborate $(100 \mathrm{mg}$, $0.5 \mathrm{mmol})$ in $20 \mathrm{ml}$ of HOAc-NaOAc $\left(0.6 \mathrm{~mol} \mathrm{dm}^{-3}\right)$ was stirred at $40{ }^{\circ} \mathrm{C}$ for $16 \mathrm{~h}$. The mixture was poured into water-dichloromethane $(100+20 \mathrm{ml})$, the organic layer was separated, washed with water, dried $\left(\mathrm{MgSO}_{4}\right)$ and the solvent evaporated. The resulting oil, consisting of $63 \%$ dibenzothiophene and $37 \%$ acetoxydibenzothiophenes (GLC), was passed through an $\mathrm{SiO}_{2}$ pad, eluting dibenzothiophene with cyclohexane-dichloromethane $(10: 1)$ and acetoxydibenzothiophenes with cyclohexanedichloromethane $(5: 1)$. Further purification of the latter on the Chromatotron provided pure samples of 4- and 1 -acetoxydibenzothiophene. None $(<0.5 \%)$ of the sulfoxide 3 was formed. The ratio of acetoxy isomers was (GLC): 1-, 53\%; 3-, 9\% and 4-, 38\%).

Nitration of 2 by $\mathrm{N}_{2} \mathrm{O}_{4}$ in dichloromethane. Dibenzothiophene $(0.18 \mathrm{~g}, 1.0 \mathrm{mmol})$ was treated with $\mathrm{N}_{2} \mathrm{O}_{4}$ $(1.5 \mathrm{mmol})$ in dichloromethane $(10 \mathrm{ml})$ for $72 \mathrm{~h}$. After aqueous work-up, GLC analysis showed the presence of $53 \%$ of starting material, $33 \%$ of sulfoxide 3 and $13 \%$ of a $3: 81: 1: 16$ mixture of 1-, 2-, 3- and 4-nitrodibenzothiophene.

Nitrous acid catalyzed nitration of 2. Dibenzothiophene $(1.0 \mathrm{~g}, 5.4 \mathrm{mmol})$ was treated with $65 \% \mathrm{HNO}_{3}(5 \mathrm{ml})$ in $25 \mathrm{ml}$ of acetic acid for $72 \mathrm{~h}$. The mixture was poured into water-dichloromethane $(100+20 \mathrm{ml})$, the organic layer was separated, washed with water, dried $\left(\mathrm{MgSO}_{4}\right)$ and the solvent evaporated. GLC analysis showed the presence of $50 \%$ of sulfoxide 3 and $50 \%$ of a $2: 81: 1: 16$ mixture of 1-, 2-, 3- and 4-nitrodibenzothiophene. This mixture was further purified by column chromatography. 
Cyclohexane-dichloromethane $(3: 1 \rightarrow 1: 1)$ eluted 1 nitrodibenzothiophene $(8)$ followed by a mixture of 4 nitro- (9) and 2-nitrodibenzothiophene (4). Further elution with methanol-dichloro-methane $(1: 3)$ yielded the pure sulfoxide (3).

Nitronium ion mediated nitration of 2 . Dibenzothiophene $(0.92 \mathrm{~g}, 5.0 \mathrm{mmol})$, sodium nitrate $(425 \mathrm{mg}, 5.0 \mathrm{mmol})$ and sodium azide $(122 \mathrm{mg}, 2.0 \mathrm{mmol})$ were stirred in $10 \mathrm{ml}$ of acetic acid. Concentrated sulfuric acid $(6 \mathrm{ml})$, dissolved in $14 \mathrm{ml}$ of acetic acid, was added slowly at $20^{\circ} \mathrm{C}$ and the mixture stirred for $24 \mathrm{~h}$. The mixture was poured into water-dichloromethane $(100+20 \mathrm{ml})$, the organic layer was separated, washed with water, dried $\left(\mathrm{MgSO}_{4}\right)$ and the solvent evaporated. GLC analysis showed the presence of $2(42 \%)$, a $2: 65: 2: 31$ mixture of 1-, 2-, 3- and 4-nitrodibenzothiophene (41\%) and the sulfoxide $3(17 \%)$.

In an exploratory experiment $2(0.18 \mathrm{~g}, 1.0 \mathrm{mmol})$ in nitromethane $(10 \mathrm{ml})$ was treated with solid nitronium tetrafluoroborate of uncertain purity for $10 \mathrm{~min}$. The reaction mixture was quenched as above and analyzed by GLC, showing the presence of $2(29 \%), 3(10 \%)$ and a $2: 79: 1: 17$ mixture of 1-, 2-, 3- and 4-nitrodibenzothiophene $(59 \%)$.

Crystallography. Crystal data, established from precession photographs and measured accurately, by means of a Siemens R3m/V four-circle diffractometer [molybdenum X-radiation, $\lambda($ Mo $K \alpha) 0.71069 \AA$, from a crystal monochromator] are given below. The space group was determined unambiguously as a result of the structure analysis reported below, but initially indicated by conditions limiting possible reflections. $\omega$-Scans were used to collect reflection intensities out to a maximum Bragg angle $\theta=25.02^{\circ}$. The cell parameters were determined by least-squares refinements for which the setting angles of 37 accurately centred high-angle reflections were used.

Crystal data. $r$-1-Hydroxy-c-4-trinitromethyl-1,4-dihydrodibenzothiophene (5), $\mathrm{C}_{13} \mathrm{H}_{9} \mathrm{~N}_{3} \mathrm{O}_{7} \mathrm{~S}, M 351.29$, monoclinic, space group $C 2 / c, a=29.207(4), b=12.714(2)$, $c=19.984(3) \AA, \quad \beta=128.94(1)^{\circ} ; \quad V=5772(2) \AA^{3}$, $D_{\mathrm{c}}=1.617 \mathrm{~g} \mathrm{~cm}^{-3}, Z=16, \mu(\mathrm{Mo} K \alpha) 2.70 \mathrm{~cm}^{-1}$. The crystal was yellow and of approximate dimensions $0.8 \times 0.54 \times 0.5 \mathrm{~mm}$. Data were collected at $148(2) \mathrm{K}$. The number of independent reflections measured was 3582, 2437 with $I>2 \sigma(I)$. Absorption corrections were not applied; $g_{1}=0.0416, g_{2}=0.0000 ; R_{\text {(obs) }}$-factor $=0.031$, $w R_{\text {(all data) }}=0.070$.

Structure determination. Full-matrix least-squares refinements (SHELXL-93) ${ }^{25}$ were employed. This program is based on intensities and uses all data. The observed threshold $I>2 \sigma(I)$ was used only for calculating $R_{\text {(obs) }}$, shown here as a comparison for the refinement based on $F$. Reflection weights $1 /\left[\sigma^{2}\left(F_{\mathrm{o}}{ }^{2}\right)+\left(g_{1} P\right)^{2}+g_{2} P\right]$, where $P=\left[F_{\mathrm{o}}{ }^{2}+2{F_{\mathrm{c}}}^{2}\right] / 3$, were used. All non-hydrogen atoms were assigned anisotropic thermal parameters. Final Fourier syntheses show no significant residual electron density, and there were no abnormal discrepancies between observed and calculated structure factors.

Acknowledgements. Financial support (to L.E.) from the Swedish Natural Science Research Council, the Knut and Alice Wallenberg Foundation and the Crafoord Foundation is gratefully acknowledged.

\section{References}

1. Eberson, L., Roos, B. O. and Shaik, S. J. Chem. Soc., Perkin Trans. 2. (1997) 463.

2. (a) Eberson, L., Hartshorn, M. P., Radner, F., Merchán, M. and Roos, B. O. Acta Chem. Scand. 47 (1993) 176; (b) Eberson, L. and Radner, F. Acta Chem. Scand. 46 (1992) 312, 802; (c) Butts, C. P., Eberson, L., Hartshorn, M. P., Robinson, W. T. and Wood, B. R. Acta Chem. Scand. 50 (1996) 587.

3. Eberson, L., Hartshorn, M. P., Persson, O., Radner, F. and Rhodes, C. J. J. Chem. Soc., Perkin Trans. 2 (1996) 1289.

4. Eberson, L., Hartshorn, M. P., Persson, O. and Radner, F. Acta Chem. Scand. 51 (1997) 492.

5. Bontempelli, G., Magno, F., Mazzocchini, G.-A. and Zecchin, S. J. Electroanal. Chem. 43 (1973) 377.

6. Eberson, L., Hartshorn, M. P. and Radner, F. In Coxon, J. M., Ed., Advances in Carbocation Chemistry, Vol. 2, JAI Press, London 1995, p. 207.

7. Eberson, L., Hartshorn, M. P. and Radner, F. Acta Chem. Scand. 48 (1994) 937.

8. Eberson, L., Hartshorn, M. P., Radner, F. and Svensson, J. O. J. Chem. Soc., Perkin Trans. 2 (1994) 1719; Eberson, L., Persson, O., Radner, F. and Hartshorn, M. P. Res Chem. Intermed. 22 (1996) 799.

9. Nyberg, K. and Wistrand, L.-G. J. Org. Chem. 43 (1978) 2613.

10. Eberson, L. J. Am. Chem. Soc. 89 (1967) 4669.

11. Baciocchi, E., Mei, S. and Rol, C. J. Org. Chem. 43 (1978) 2919.

12. Bosch, E. and Kochi, J. K. J. Org. Chem. 59 (1994) 3314.

13. Ridd, J. H. Chem. Soc. Rev. 20 (1991) 149.

14. Radner, F., Robinson, W. T. and Wood, B. R., 1997 and references cited therein.

15. Olah, G. A., Balaram Gupta, B. G. and Narang, S. C. J. Am. Chem. Soc. 101 (1979) 5317.

16. Adam, W. and Nunez, E. G. Tetrahedron Lett. 47 (1991) 3773 .

17. Cullinane, N. M., Davies, C. G. and Davies, G. I. J. Chem. Soc. (1936) 1435.

18. Eberson, L. and Radner, F. J. Am. Chem. Soc. 113 (1991) 5825.

19. Eberson, L., Hartshorn, M. P., Persson, O. and Radner, F. J. Chem. Soc., Chem. Commun. (1996) 2105.

20. Butts, C. P., Eberson, L. and Hartshorn, M. P. Acta Chem. Scand. 51 (1997) 718. Eberson, L., Hartshorn, M. P., Radner, F. and Svensson, J. O. Acta Chem. Scand. 50 (1996) 885.

21. Radner, F. and Eberson, L. J. Chem. Res. (S) (1996) 362.

22. Tschinkel, J. G. Ind. Eng. Chem. 48 (1965) 732.

23. Gilman, H. and Jacoby, A. L. J. Org. Chem. 3 (1938) 108.

24. Gilman, H., Jacoby, A. L. and Pacevitz, H. A. J. Org. Chem. 3 (1938) 120.

25. Gerdil, R. and Lucken, E. A. C. J. Am. Chem. Soc. 97 (1997) 213. 
26. See, e. g. (a) Butts, C. P., Calvert, J. L., Eberson, L., Hartshorn, M. P., Maclagan, R. G. A. R. and Robinson, W. T. Aust. J. Chem. 47 (1994) 1087; (b) Calvert, J. L., Eberson, L., Hartshorn, M. P., Maclagan, R. G. A. R. and Robinson, W. T. Aust. J. Chem. 47 (1994) 1211, 1591; (c) Butts, C. P., Calvert, J. L., Eberson, L., Hartshorn, M. P., Radner, F. and Robinson, W. T. J.Chem. Soc.,
Perkin Trans. 2 (1994) 1485; (d) Calvert, J. L., Eberson, L., Hartshorn, M. P., Robinson, W. T. and TimmermanVaughan, D. J. Acta Chem. Scand. 48 (1994) 917. 27. Sheldrick, G. M. J. Appl. Crystallogr. In preparation.

Received December 4, 1996. 